\title{
HORIZONTAL ALVEOLAR RIDGE AUGMENTATION USING XENOGENIC BONE GRAFT: A COMPARISON BETWEEN THE FLAP AND SUBPERIOSTEAL TUNNELING TECHNIQUES
}

\author{
Mohammed Omran Hamed * and Mahmoud Mohsen El Arini**
}

\begin{abstract}
Background: The aim of this study was to evaluate the prognosis of minimal invasive horizontal alveolar ridge augmentation using small incision and subperiosteal tunneling technique.

Methods: This study was conducted on 10 partially edentulous patients with horizontal alveolar bone deficiency in 12 areas that need horizontal alveolar ridge augmentation for future implant placement. Cone beam computer tomography was done for sites that need implant placement preoperatively. Xenogeneic bone was used for grafting deficient horizontal alveolar ridge sites using the flap technique in 6 areas and using the subperiosteal tunneling technique in another 6 areas for future implant placement. Cone beam computer tomography was done for grafted sites immediately postoperative and 6 months postoperative.
\end{abstract}

Results: This study was conducted on 10 patients and included 12 implant sites. No complications related to bone grafting were found and there was an adequate clinical prognosis. Regarding the difference from pre-operatively to 6 months post-operatively, a slightly higher increase in ridge width was recorded in subperiosteal tunnel group $(1.48 \pm 0.99)$ in comparison to flap group $(0.91 \pm 0.94)$, with no statistically significant difference $(\mathrm{p}=0.086)$.

Conclusions: The bone graft material retained within a pouch formed using small incision and subperiosteal tunneling technique resulted in additional increase within the width of the alveolar ridge than the flap technique.

KEYWORDS: alveolar ridge augmentation, Dental implants, xenogeneic bone graft and subperiosteal tunneling technique.

* OMFS, Faculty of Dentistry, BeniSuef University, BeniSuef, Egypt

** OMFS, Faculty of Dentistry, Future University, Cairo, Egypt 


\section{INTRODUCTION}

Ridge augmentation techniques are indicated to gain sufficient alveolar bone volume for dental implant placement in partial or complete edentulous patients. ${ }^{(1)}$

Restoration of bone volume in patients with atrophic ridges may be a prerequisite to esthetic and functional implant supported prosthetic rehabilitation. ${ }^{(2)}$

Several techniques are described to enhance bone volume, including ridge splitting, distraction osteogenesis, guided bone regeneration (GBR), corticocancellous block onlay, and interpositional bone grafts, etc. ${ }^{(3-7)}$

A variety of graft materials are used and many surgical approaches exist. A standered approach consists of raising a full thickness mucoperiosteal flap to access the deficient area and insert auto graft, allograft, xenograft, alloplastic or combination. ${ }^{(8-9)}$

Grafts may be combined with tissue barriers. Various guided bone regeneration (GBR) methods have been clinically trialed for their effectiveness ${ }^{(10-12)}$. In guided bone regeneration, flap technique is employed and this done by horizontal incision within the alveolar crest and two vertical incisions and reflection of the periosteum.

Autogenous bone is considered the gold standard for augmentation of deficient alveolar ridge areas to facilitate implant placement. ${ }^{(13)}$. However, usage of autogenous bone carries the drawbacks of additional donor site surgery and its complications. Therefore several materials have been developed as bone graft substitutes to autogenous bone. ${ }^{(14)}$.

Onlay grafting seems to be one among the foremost predictable of those techniques. But their complications are wound dehiscence and graft exposure and loss. ${ }^{(15)}$.

The risk of bone exposure and loss of the graft material is increased with the utilization of crestal full thickness incisions for surgical access. Management of the flap for grafting necessitates surgical wound closure directly over the bone graft. Hence, any dehiscence at the wound margins of the crestal incision results in exposure of the graft, increasing the likehood of contamination and failure. Reports have suggested a modification of the surgical approach to decrease the risk of graft exposure $^{(16)}$.

The subperiosteal augmentation techniques involve placement of vertical incisions far away from the actual site of bone grafting. Subperiosteal tunneling is created to reach the deficient site. This enables the graft material to be placed under intact mucoperiosteal tissue, thereby decreasing the risk of exposure of the graft and wound dehiscence. ${ }^{(16)}$

Though early membrane exposure does not necessarily end in failure in bone augmentation, it is believed that the exposed graft site will influence the prognosis of the graft by inducing infection and causing bone loss. It has been reported that early membrane exposure had a serious negative effect on bone regeneration ${ }^{(17)}$. Moreover, this excessive tension on the suture line could end in soft tissue dehiscence, which is an undesirable complication especially where esthetics is of concern.

Minimal invasive horizontal ridge augmentation (MIHRA) employing subperiosteal tunneling technique was suggested by Kent et al. during which a vertical incision was made in the alveolar ridge and hydroxyapatite particles was injected under the periosteum $^{(18)}$. The graft showed some success initially, but hydroxyapatite particles showed instability and fibrous capsule was observed preventing new bone formation ${ }^{(19-20)}$. Studies about MIHRA showed slow progress since that time.

Subperiosteal tunneling technique may be a partially blind procedure that needs delicate surgical maneuvers to develop the subperiosteal flap that could form. This bone augmentation technique has advantages of less postoperative complications. ${ }^{(18-20)}$. Prognosis of 
horizontal ridge augmentation by vertical incision and subperiosteal tunneling method was evaluated in our study.

\section{MATERIALS AND METHODS}

\section{Inclusion criteria}

The inclusion criteria were as follow:

- Patients have missing teeth and want replacement by dental implants.

- Deficient horizontal alveolar ridge which need bone grafting for future implant placement.

\section{Exclusion criteria}

From the medical record, patients with subsequent criteria were not included in our study:

1. The presence of uncontrolled diabetes or any other systemic condition which may contraindicate the surgical procedure.

2. Radiotherapy to the head and neck region in the last 12 months.

3. Chemotherapy within the last 12 months.

4. Uncontrolled periodontitis

5. Smoking habit of 20 cigarettes or more per day.

6. Psychological problem.

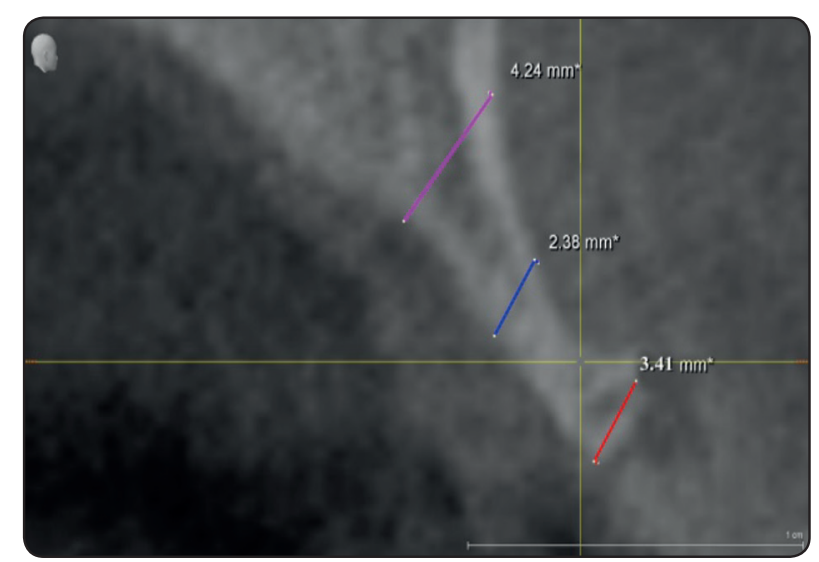

Fig. (1) The flap technique: preoperative Cone beam computer tomography

\section{Preoperative preparation}

A complete clinical examination of oral cavity was carried out, Pre-operative cone beam computer tomography was obtained for each patient (fig.1, fig 2 ), and treatment plan was disscused. The patients received oral hygiene instructions, chlorhexidine mouth wash* three times daily and full-mouth prophylaxis prior to the surgery. Antibiotic prophylaxis initiated the day prior to surgery $1 \mathrm{~g}$ (amoxicillin+clavulanic acid) ** 2 times daily.

\section{Surgical technique}

The surgical armamentarium was prepared. The patients were prepared in a routine aseptic manner. The surgery was performed under local anesthesia.

\section{The flap technique}

Crestal horizontal incision was made using bard barker blade No.15 at the anticipated site for future implant placement. Two vertical realizing incisions were made buccally. Full thickness mucoperiosteal flaps were reflected using mucoperiosteal elevator. After dissection finished, decortication of the alveolar ridge was performed using round surgical bur mounted on low-speed hand piece (fig.3). Bovine bone (hypr-Oss)* was mixed with saline and inserted into the deficient area. Next a collagen membrane was adapted, bent and inserted under the flap. It is important to suture the flap within the membrane.

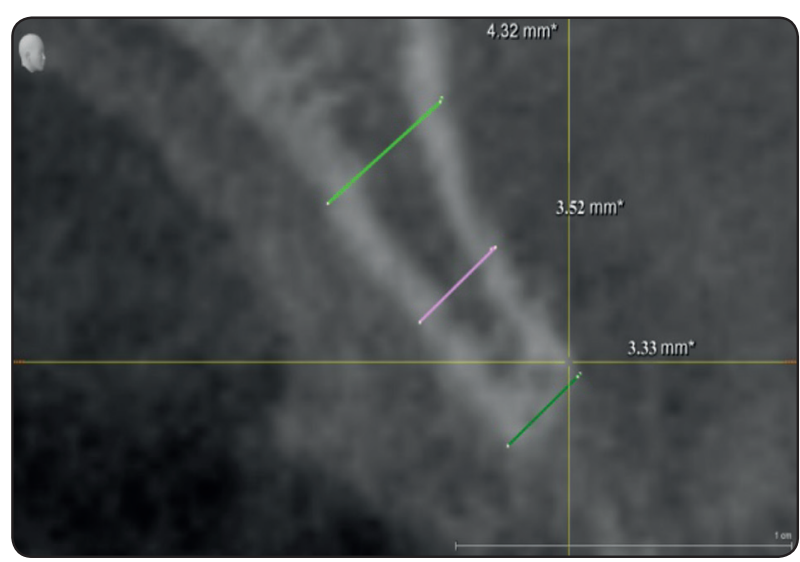

Fig. (2) Subperiosteal tunneling technique: preoperative Cone beam c.t. 


\section{Subperiosteal tunneling technique}

A vertical incision was performed mesial or distal to the region to be grafted. The incision was made down to bone. Then tissues were dissected and a subperiosteal pocket was formed using periosteal elevator. The periosteum was elevated from the alveolar bone forming pocket. Care must be taken not to dissect lingual and palatal tissues or muscle attachments. After dissection finished and a pocket was obtained, decortication of the alveolar ridge was performed using round bur mounted on low-speed hand piece. In the posterior areas, decortications were also performed, taking care to protect the dissected tissues with periosteal elevator during the procedure. Next a collagen membrane was adapted, bent and inserted under the pocket. The membrane was inserted as posterior as possible to be sure that the flap was elevated completely. Bovine bone (hypr-Oss*) was mixed with saline and inserted into the deficient area using plastic syringe. The bone graft was packed into the site and the incision was sutured. (fig.4)

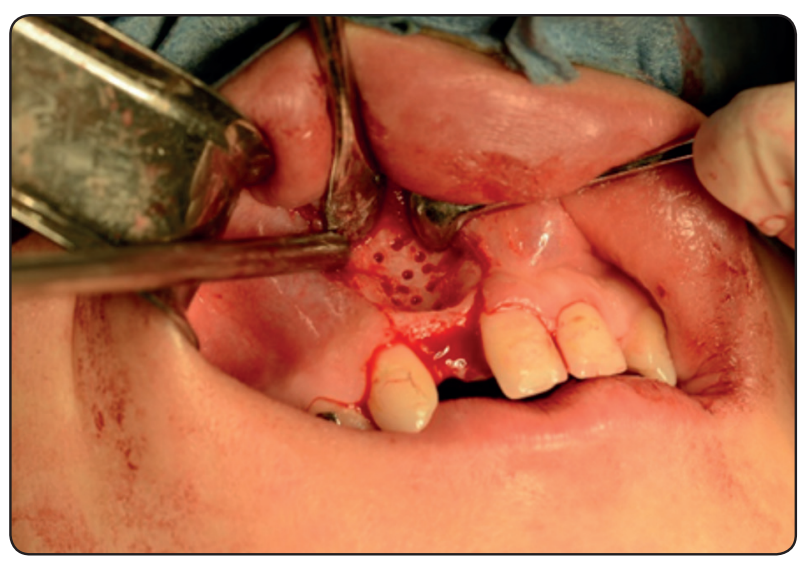

Fig. (3) The flap technique

\section{Postoperative management:}

Medication was prescribed include chlorhexidine mouth wash** three times daily for 14 days, Antibiotic one g (amoxicillin+clavulanic acid) $* * *$ two times daily for seven days, and Non-steroidal Anti-inflammatory drug $400 \mathrm{mg}$ ibuprofen**** three times daily for seven days.

\section{Follow up}

Clinical evaluation for all cases at the following periods:

- Immediately after surgery.

- Two weeks after surgery.

- 6 months after surgery.

- The presence of any complications was recorded and categorized as:

- Operative complications such as excessive bleeding

- Postoperative complications such as swelling, ecchymosis, pain, wound dehiscence.

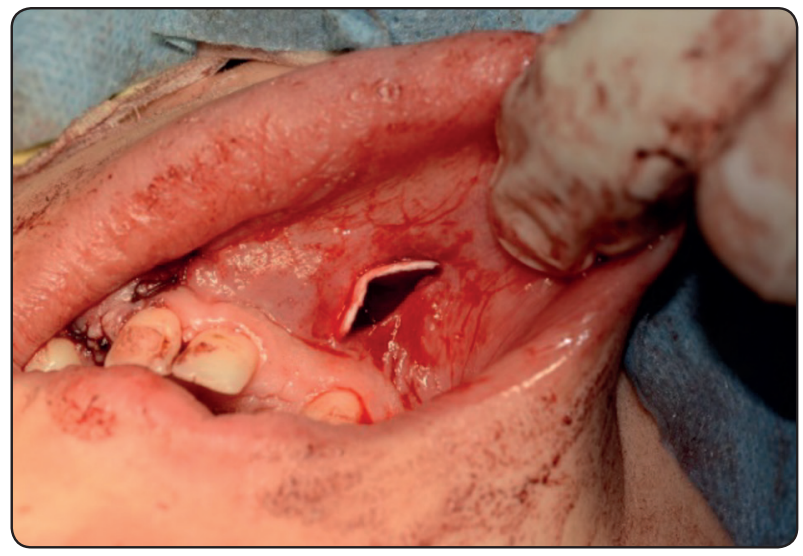

Fig. (4) Subperiosteal tunneling technique

\footnotetext{
*Hypro-Oss:Bioimplon Gmbh, Germany

**Antiseptol: Kahira Com.

***Augmentin: Glaxosmithklin.

****Brufen: ABBOT Kahira Pharma \& Chem.Ind.Co
} 
Radiographic evaluation was performed using cone beam CT immediately after surgery and 6 months after surgery.

The aim of the radiographic analysis was to determine on consecutive radiographs: the width of the alveolar bone preoperatively, immediately after bone grafting, and 6 months postoperatively.

\section{Statistical analysis}

Statistical analysis was performed using software program (SPSS 18; SPSS, Chicago,IL,USA). Values were presented as mean and standard deviation (SD) and confidence intervals. Data were explored using Kolmogorov-Smirnov test of normality. Since most data were parametric, independent $t$ test was used to compare the 2 groups. Chi square test was used to compare gender distribution in both groups. The significance level was set at $\mathrm{P} \leq 0.05$.

\section{RESULTS}

\section{Clinical evaluation}

Healing after grafting procedures was uneventful in all patients. None of the patients developed complications such as wound dehiscence, infection, or fistula formation. The mucosa over the graft material was in good condition in all patients.

\section{Demographic data}

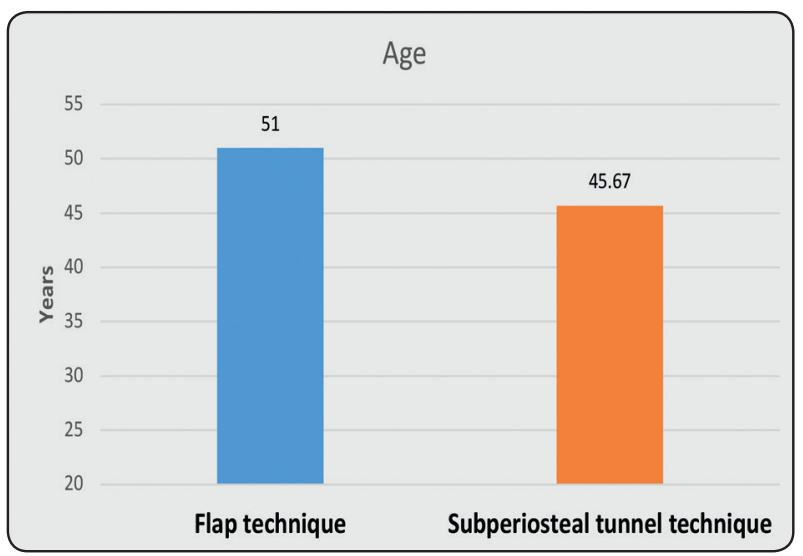

Fig. (5) Bar chart illustrating mean age (years) in both groups
Regarding age, a slightly higher mean value $(51 \pm 13.1)$ was recorded in flap group, in comparison to $(45.67 \pm 12.42)$ in subperiosteal tunnel group. This difference was not statistically significant $(\mathrm{p}=0.486)$. (Table 1, Fig.5)

Regarding gender, flap group consisting of 3 males and 3 females, while subperiosteal tunnel group consisted of 2 males and 4 females. This difference was not statistically significant $(\mathrm{p}=0.558)$, (Table 1, Fig.6)

TABLE (1) Demographic data of patients in both groups

\begin{tabular}{|l|l|l|l|}
\hline & $\begin{array}{l}\text { Flap } \\
\text { technique }\end{array}$ & $\begin{array}{l}\text { Subperiosteal } \\
\text { tunnel technique }\end{array}$ & P \\
\hline Age (yrs) & $51 \pm 13.1$ & $45.67 \pm 12.42$ & $0.486 \mathrm{~ns}$ \\
\hline Gender & $\begin{array}{l}3 \text { males } \\
3 \text { Females }\end{array}$ & $\begin{array}{l}2 \text { males } \\
\text { 4 females }\end{array}$ & $0.558 \mathrm{~ns}$ \\
\hline
\end{tabular}

Significance level $p \leq 0.05$, ns=non-significant

\section{Radiographic evaluation}

\section{Comparison of ridge width between groups}

Results of ridge width are summarized in Table $(2,3)$ and in Figure (7-12)

Pre-operatively, there was no significant difference between groups $(\mathrm{p}=0.531)$

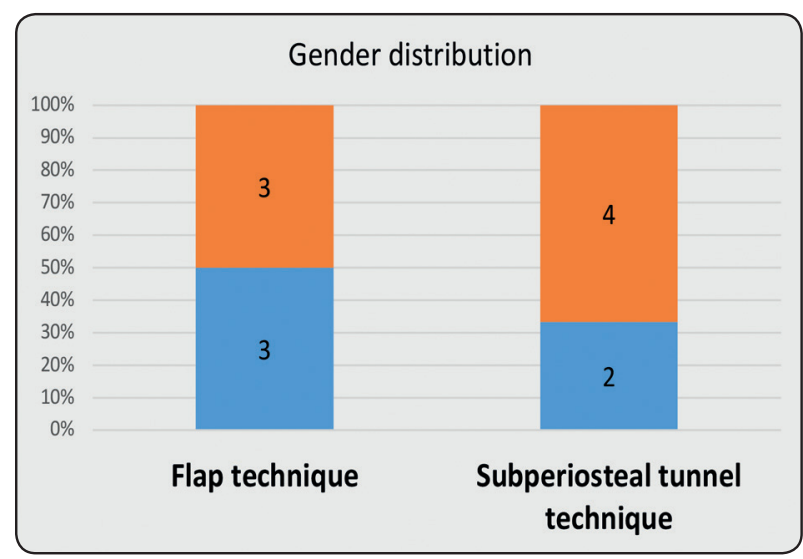

Fig. (6) Bar chart illustrating gender distribution in both groups 
Immediately postoperative, a slightly higher mean value was recorded in subperiosteal tunnel group $(5.69 \pm 1.42)$ in comparison to flap group $(5.41 \pm 1.72)$, with no statistically significant difference $(\mathrm{p}=0.593)$

Six months post operatively, a slightly higher mean value was recorded in subperiosteal tunnel group $(5.21 \pm 1.23)$ in comparison to flap group $(4.91 \pm 1.57)$, with no statistically significant difference $(\mathrm{p}=0.593)$

Regarding the difference from preoperatively to immediately post-operatively, a slightly higher mean increase in ridge width was recorded in subperiosteal tunnel group $(1.96 \pm 1.2)$

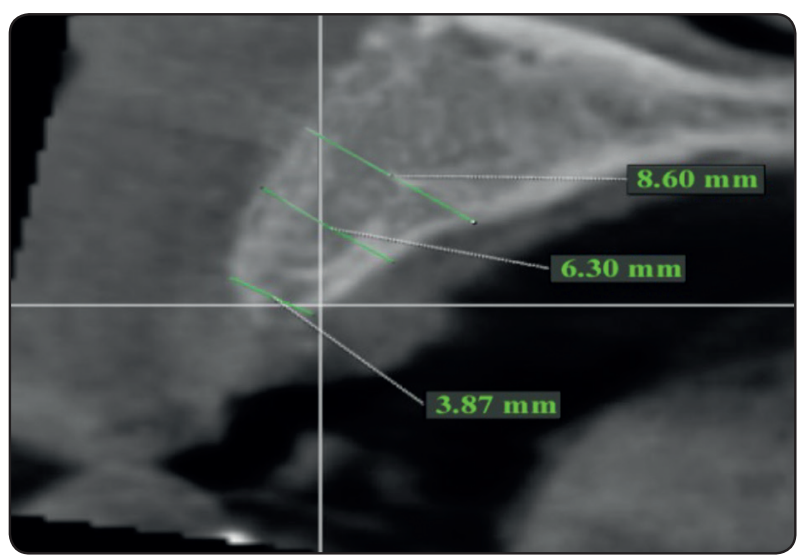

Fig. (7) The flap technique: immediately postoperative

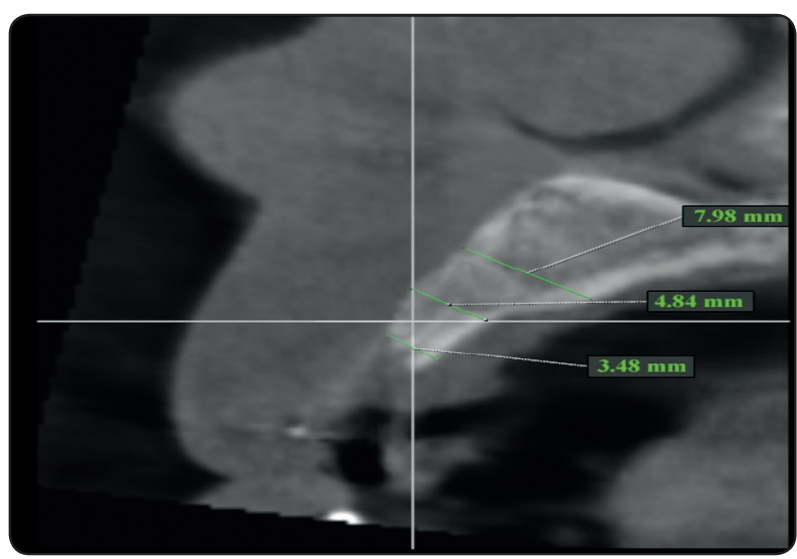

Fig. (9) The flap technique: 6 months postoperative in comparison to flap group $(1.41 \pm 1.09)$, with no statistically significant difference $(\mathrm{p}=0.159)$

Regarding the difference from immediately post-operatively to 6 months post-operatively), a slightly less mean decrease in ridge width was recorded in subperiosteal tunnel group $(-0.48 \pm 4.3)$ in comparison to flap group $(-0.50 \pm 0.33)$, with no statistically significant difference $(\mathrm{p}=0.863)$

\section{Regarding the difference from pre-operatively} to 6 months post-operatively), a slightly higher increase in ridge width was recorded in subperiosteal tunnel group (1.48 \pm 0.99$)$ in comparison to flap group $(0.91 \pm 0.94)$, with no statistically significant difference $(\mathrm{p}=0.086)$

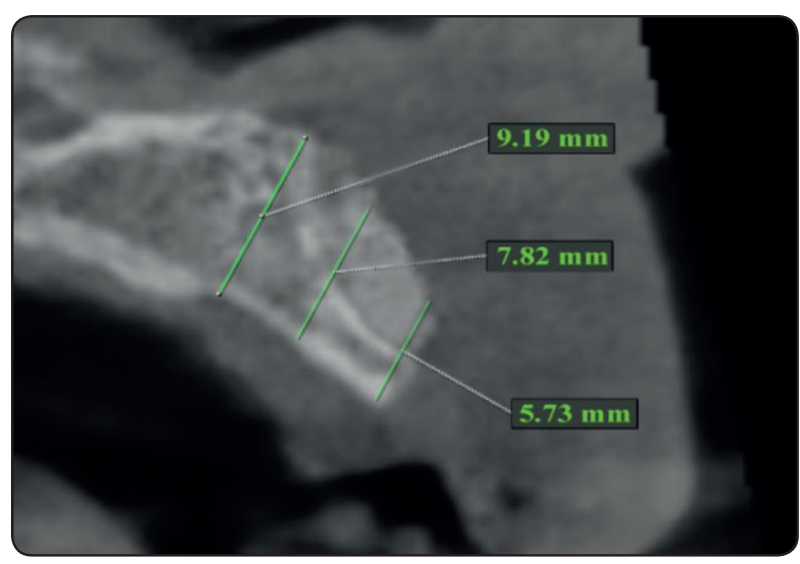

Fig. (8) Subperiosteal tunneling technique: immediately postoperative

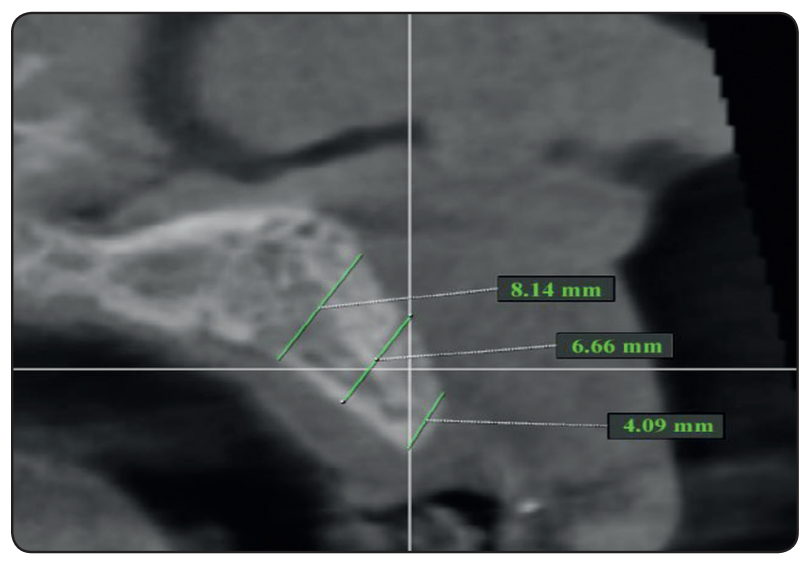

Fig. (10) Subperiosteal tunneling technique 6 months postoperative 
TABLE (2) Descriptive statistics and comparison of ridge width between both groups

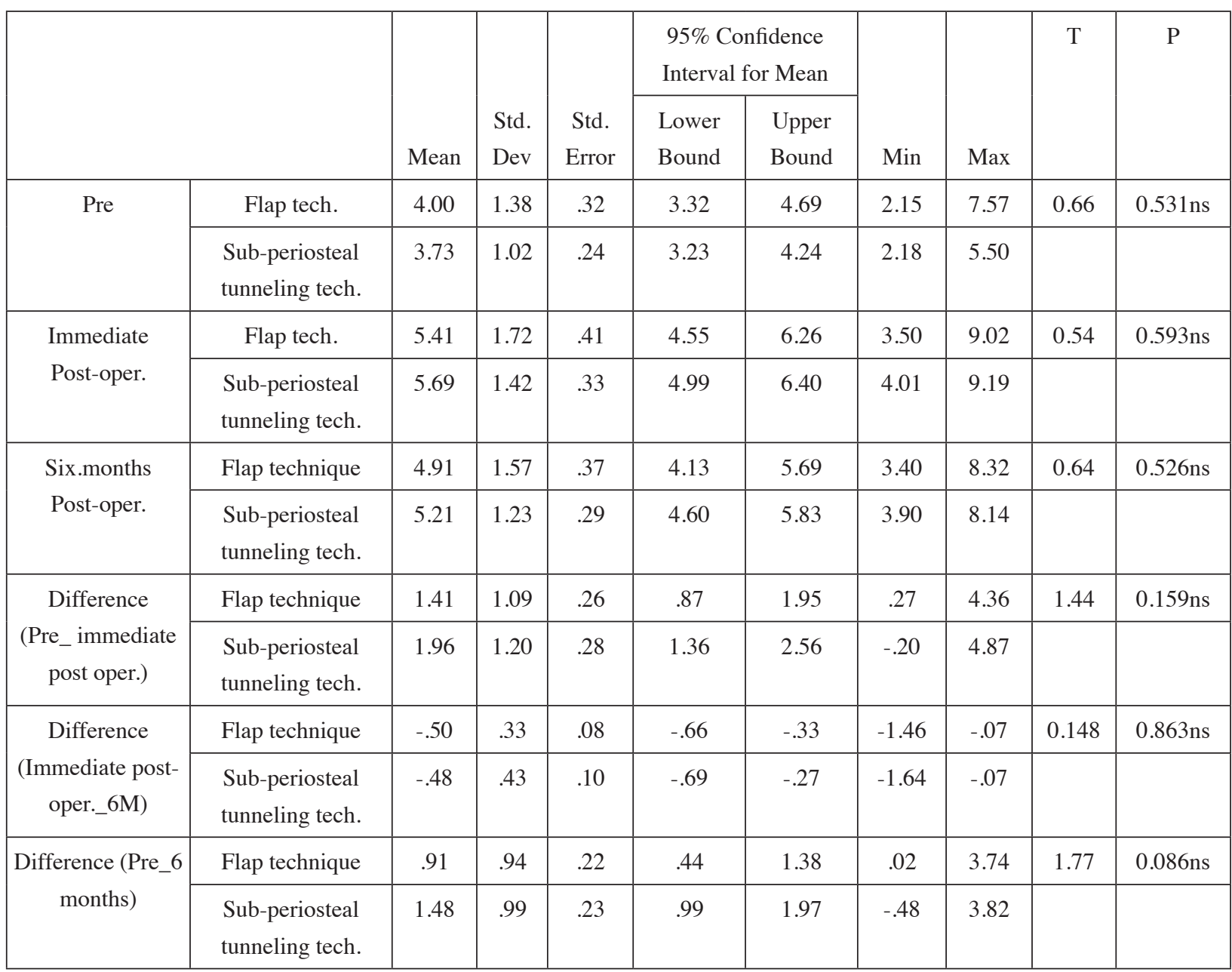

\section{Significance level $p \leq 0.05, n s=n o n$-significant}

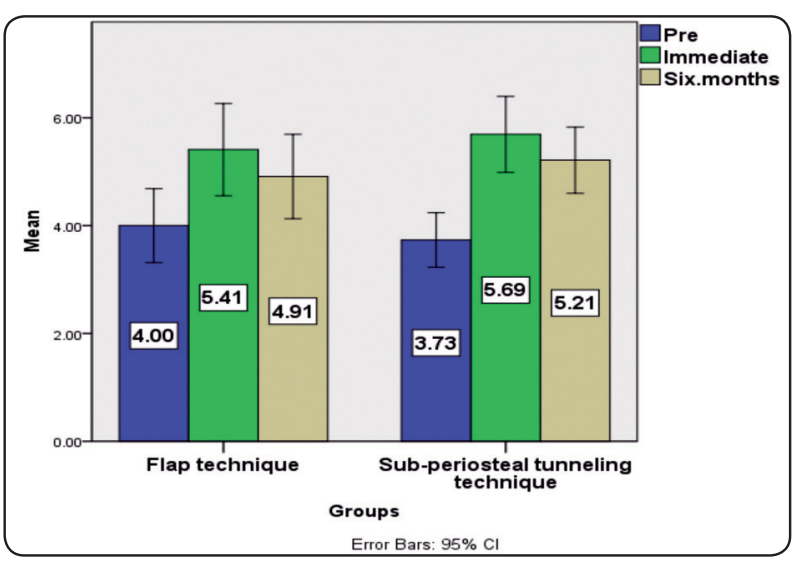

Fig. (11) Bar chart illustrating mean values of ridge width in flap and subperiosteal tunneling technique

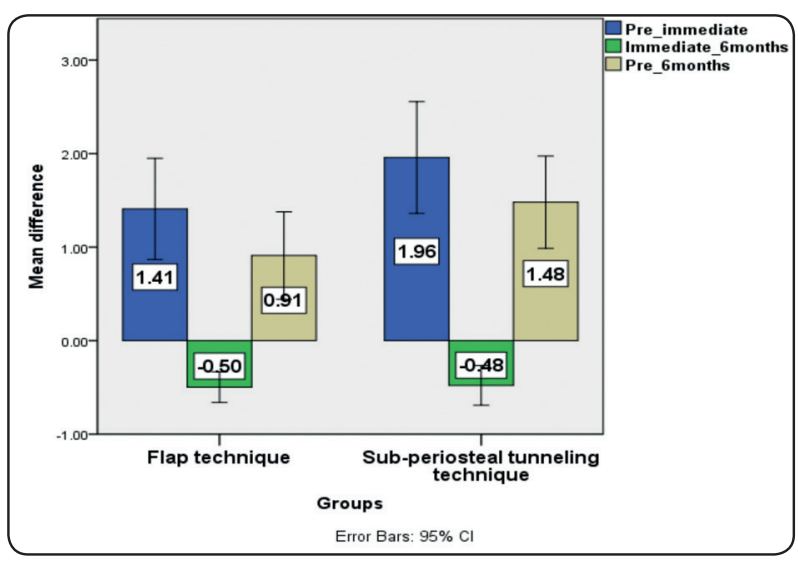

Fig. (12) Bar chart illustrating mean difference of ridge width in Flap and subperiosteal tunneling technique in different intervals 


\section{Comparison of different observations within the same group}

In flap technique, a significantly higher mean value was recorded immediately postoperatively $(5.41 \pm 1.72)$, in comparison to pre-operatively $(4 \pm 1.38),(\mathrm{p}=0.00)$. Moreover, a significantly higher mean value was recorded 6 months postoperatively $(4.91 \pm 1.57)$, in comparison to pre-operatively (4 \pm 1.38$), \quad(\mathrm{p}=0.001)$. However, a significantly higher mean value was recorded immediately postoperatively (5.41 \pm 1.72$)$, in comparison to 6 months postoperatively $(4.91 \pm 1.57),(\mathrm{p}=0.00)$.

TABLE (3) Descriptive statistics and comparison of ridge width at different observations within the same group

\begin{tabular}{|c|c|c|c|c|c|}
\hline \multicolumn{2}{|c|}{ Groups } & \multirow{2}{*}{$\frac{\text { Mean }}{4.00}$} & \multirow{2}{*}{$\begin{array}{l}\text { Std. } \\
\text { Dev }\end{array}$} & \multirow{2}{*}{$\begin{array}{c}\mathrm{t} \\
-5.49\end{array}$} & \multirow{2}{*}{$\begin{array}{c}\mathrm{p} \\
.000 *\end{array}$} \\
\hline \multirow{6}{*}{ 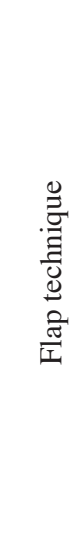 } & Pre-operative & & & & \\
\hline & $\begin{array}{l}\text { Immediate post- } \\
\text { operative }\end{array}$ & 5.41 & 1.72 & & \\
\hline & Pre-operative & 4.00 & 1.38 & -4.11 & $.001 *$ \\
\hline & $\begin{array}{l}\text { Six months post- } \\
\text { operative }\end{array}$ & 4.91 & 1.57 & & \\
\hline & $\begin{array}{l}\text { Immediate post- } \\
\text { operative }\end{array}$ & 5.41 & 1.72 & \multirow[t]{2}{*}{6.40} & \multirow[t]{2}{*}{$.000 *$} \\
\hline & $\begin{array}{l}\text { Six months post- } \\
\text { operative }\end{array}$ & 4.91 & 1.57 & & \\
\hline \multirow{6}{*}{ 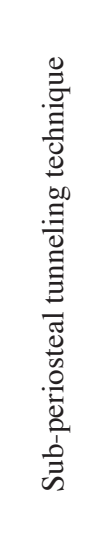 } & Pre -operative & 3.73 & 1.02 & -6.91 & $.000 *$ \\
\hline & $\begin{array}{l}\text { Immediate post- } \\
\text { operative }\end{array}$ & 5.69 & 1.42 & & \\
\hline & Pre -operative & 3.73 & 1.02 & -6.33 & $.000 *$ \\
\hline & $\begin{array}{l}\text { Six months post- } \\
\text { operative }\end{array}$ & 5.21 & 1.23 & & \\
\hline & $\begin{array}{l}\text { Immediate } \\
\text { post-operative }\end{array}$ & 5.69 & 1.42 & \multirow[t]{2}{*}{4.75} & \multirow[t]{2}{*}{$.000 *$} \\
\hline & $\begin{array}{l}\text { Six months post- } \\
\text { operative }\end{array}$ & 5.21 & 1.23 & & \\
\hline
\end{tabular}

Significance level $p \leq 0.05, n s=n o n$-significant
In subperiosteal tunnel technique, a significantly higher mean value was recorded immediately postoperatively $(5.69 \pm 1.42)$, in comparison to pre-operatively $(3.73 \pm 1.02)$, $(\mathrm{p}=0.00)$. Moreover, a significantly higher mean value was recorded 6 months postoperatively $(5.21 \pm 1.23)$, in comparison to pre-operatively $(3.73 \pm 1.02), \quad(p=0.00)$. However, a significantly higher mean value was recorded immediately postoperatively $(5.69 \pm 1.42)$, in comparison to 6 months postoperatively $(5.21 \pm 1.23),(\mathrm{p}=0.00)$.

\section{DISCUSSION}

In oral and maxillofacial surgery, vertical or horizontal bone augmentation is necessary to achieve adequate bone volume especially when placing dental implants in partial or complete edentulous patients.

Several bone grafting techniques and materials have been advised to reconstruct adequate bone volume in deficient areas of the alveolar bone. These techniques include horizontal alveolar ridge augmentation using bone grafting materials and guided bone regeneration.Early membrane exposure, which causes infection and wound dehiscence, is a major complication with conventional ridge augmentation techniques.

It has been reported that the thin posterior mandibular ridge can be successfully managed by horizontal ridge augmentation with particulate human mineralized bone ${ }^{(21)}$.this coincides with our results that showed significantly higher mean value of horizontal bone gain recorded 6 months postoperatively $(5.21 \pm 1.23)$, in comparison to preoperatively $(3.73 \pm 1.02)$,

There are several advantages of the horizontal alveolar ridge augmentation through minimally invasive technique compared to conventional horizontal alveolar bone augmentations. The minimally invasive method is relatively less morbid and it does not require flap elevation as seen in our study 
The present study showed a slightly higher increase in ridge width in subperiosteal tunnel group $(1.48 \pm 0.99)$ in comparison to flap group $(0.91 \pm 0.94)$, regarding the difference from preoperatively to 6 months post-operatively, with no statistically significant difference $(\mathrm{p}=0.086)$. The rationale for the varied outcomes of the two procedures is presumably explained by the effect of the periosteum. Within the flap procedure, an incision is made through the periosteum to advance the flap over the graft and to achieve primary closure without tension, which results that the graft material not completely covered with the periosteum. In contrast, with the tunnelling procedure, the periosteum is lifted without flap elevation or a releasing incision of the periosteum. the periosteum is the source of mesenchymal cells and osteoblasts that are important in osteogenesis,. The preservation of the periosteum optimizes bone formation. ${ }^{(22-25)}$

The tunneling technique is believed to become one of the foremost vital methods for enhancing bone formation. additionlly, the subperiosteal tunneling procedure is attractive because it's minimally invasive. The technique offers the advantages of a more conservative surgical entry and little postoperative morbidity than the flap procedure, thereby shortening surgical time and minimizing the extent of postoperative pain, edema, and infection ${ }^{(26)}$. This agreed our results as all the grafts healed successfully with no rejection of any case. No signs of infection or wound dehiscence were reported through the follow-up period.

The bone graft material might have less movement when the subperiosteal tunnel technique is used because the graft is stabilized in its pocket than with the open approach. In the present study, we proved that new bone formation was more in the subperiosteal tunnel technique than flap technique. Therefore, it is likely that the greater bone formation in the tunnelling group would have been influenced by the graft stabilization,
Subperiosteal tunnelling procedure with a BioOss block onlay graft is used in atrophic areas of the mandible when less than $6 \mathrm{~mm}$ of bone augmentation is needed. ${ }^{(26)}$ However, in our study more than $6 \mathrm{~mm}$ of bone augmentation was achieved using a subperiosteal tunnelling procedure and flap technique with xenogeneic bone graft

Based on the data presented in our study, bone formation in the grafted site is significantly greater when a tunnelling procedure is used to place xenogeneic bone for horizontal alveolar augmentation than when we use the flap technique. These results coincided with the results of Feng Xuan et al who stated that bone formation within the graft site is significantly greater when a tunnelling procedure is used to place Bio-Oss blocks for vertical ridge augmentation than when we use the flap technique. ${ }^{(26)}$

Commonly, full flap is raised (open approach) and bone graft is delivered to the deficient areas that are candidates for future implant insertion. Lateral ridge augmentation using the sub periosteal tunnelling dissection is a closed and partially blind procedure, because it doesn't permit viewing the deficient ridge, but it enables access to the recipient area with minimal tissue dissection and handling. ${ }^{(27)}$

Although others have performed augmentation of the lateral ridge without use of tissue barriers, ${ }^{(28)}$ we believe that usage of membrane to create a tent effect will keep the dissected tissue raised, permitting insertion of the bone graft material, allowing an increase in volume of the deficient area and preventing the ingress of unwanted tissues such as fibroblasts into the graft

Bovine bone is a reliable source for bone grafting. It has osteoinductive properties that promote new bone formation. ${ }^{(29)}$ Bovine bone is also easy to handle and is easily packed under the elevated and dissected pocket.

Although different kinds of bone grafting materials from other areas of the body (such as iliac 
crest, calvaria, tibia, chin, or external oblique line from the mandible) are available and are commonly used in oral and maxillofacial surgery, ${ }^{(30-35)}$ patients are usually more receptive to a procedure that's minimally invasive and doesn't require a secondary surgical site. Because the pocket technique is indeed a minimally invasive procedure that doesn't require a secondary site for bone harvesting, patients benefit from less pain and rapid recovery.

\section{CONCLUSION}

Alveolar ridge augmentation using subperiosteal tunnelling could be a minimally invasive procedure that permits access to the lateral alveolar ridge. Based on the data presented in this study, bone formation in the grafted site is greater when subperiosteal tunnelling procedure is used to place xenogeneic bone for horizontal alveolar ridge augmentation than when flap procedure is used. A more sample size may be required with longer follow up period to obtain a conclusive result for bone width gain using subperiosteal tunnelling technique.

\section{REFERENCES}

1. Cordaro L, Amade DS, Cordaro M. Clinical results of alveolar ridge augmentation with mandibular block bone grafts in partially edentulous patients prior to implant placement. Clin Oral Impl Res 13:103-111(2002)

2. Scipioni A, Bruschi GB, Calesini G. The edentulous ridge expansion technique: a five-year study. Int J Periodontics Restorative Dent 14(5):451-459 (1994).

3. Yun KI, Choi H, Wright RF. Efficacy of alveolar vertical distraction osteogenesis and autogenous bone grafting for dental implants: systematic review and meta-analysis. Int J Oral Maxillofac Implants 31(1):26-36 (2016).

4. Proussaefs P, Lozada J, Rohrer MD. A clinical and histologic evaluation of a block onlay graft in conjunction with autogenous particulate and inorganic bovine material: a case report. Int J Periodontics Restorative Dent 22:567 (2002).

5. Restoy-Lozano A, Dominguez-Mompell JL, InfanteCossio P. Reconstruction of mandibular vertical defects for dental implants with autogenous bone block grafts using a tunnel approach: clinical study of 50 cases. Int J Oral Maxillofac Surg 44(11):1416-1422 (2015).

6. Khoury F, Hanser T. Mandibular bone block harvesting from the retromolar region: a 10-year prospective clinical study. Int J Oral Maxillofac Implants 30(3):688-697 (2015).

7. Jeong SM, Choi BH, Li J, Xuan F. Simultaneous flapless implant placement and peri-implant defect correction: an experimental pilot study in dogs. J Periodontol 79(5):876880 (2008).

8. Buser D, Dula K, Hirt HP, Schenk RK. Lateral ridge augmentation using autografts and barrier membranes. A clinical study with 40 partially edentulous patients. J Oral Maxillofac Surg; 54:420-32 (1996).

9. Block MS. Treatment of the single tooth extraction site: Oral Maxillofac Surg Clin N Am; 16:41-63 (2004).

10. Tamimi F, Torres J, Lopez-Cabarcos E, Bassett D, Habibovic P, Luceron E et al. Minimally invasive maxillofacial vertical bone augmentation using brushite based cements. Biomaterials 30:208-216 (2009).

11. Nevins ML, Camelo M, Nevins M, Schupbach P, Friedland B, Camelo JMB, David M. Minimally invasive alveolar ridge augmentation procedure using rhPDGF-BB in combination with three matrices: a case series. Int $\mathrm{J}$ Periodontol \& Res Dent 29(4):370-383 (2009).

12. Allen EP, Gainza CS, Farthing GG, Newbold DA. Improved technique for localized ridge augmentation: a report of 21 cases. J Periodontol 56(4):195-199 (1985).

13. Buser D (ed) 20 years of guided bone regeneration in implant dentistry, 2nd edn. Quintessence Pub Co, Chicago (2009).

14. Jensen SS, Terheyden H. Bone augmentation procedures in localized defects in the alveolar ridge: clinical results with different bone grafts and bone substitute materials. Int $\mathrm{J}$ Oral Maxillofac Implants 24(Supple):218-236 (2009).

15. Block MS, Degen M. Horizontal ridge augmentation using human mineralized particulate bone: preliminary results. J Oral Maxillofac Surg 62(9 Suppl 2):67-72 (2004).

16. Hasson O. Augmentation of deficient lateral alveolar ridge using the subperiosteal tunneling dissection approach. Oral Surg Oral Med Oral Pathol Oral Radiol Endod 103(3):1419 (2007). 
17. LeGeros RZ. Properties of osteoconductive biomaterials: calcium phosphates. Clin Orthop Relat Res 395:81-98 (2002).

18. Artzi Z, Weinreb M, Givol N, Rohrer MD, Nemcovsky CE, Prasad HS, Tal H. Biomaterial resorptionrateand healing site morphology of inorganic bovine bone and $\beta$-tricalciumphosphatein the canine: a 24 month longitudinal histologic study and morphometric analysis. Int J Oral Maxillofac Implants 19(3):357-368 (2004).

19. Jensen SS, Broggini N, Hjørting-Hansen E, Schenk R, Buser D. Bone healing and graft resorption of autograft, anorganic bovine bone and $\beta$-tricalcium phosphate. A histologic and histomorphometric study in the mandibles of minipigs. Clin Oral Implants Res 17(3):237-243 Nair (2006).

20. Nair PNR, Luder H-U, Maspero FA, Fischer JH, Schug J. Biocompatibility of b-tricalcium phosphateroot replicas in porcine tooth extraction sockets - a correlative histological, ultrastructural, and X-ray (2006).

21. Block MS, Degen M. Horizontal ridge augmentation using human mineralized particulate bone: preliminary results. J Oral Maxillofac Surg 62(2):67-72 (2004).

22. Allen MR, Hock JM, Burr DB. Periosteum: Biology, regulation, and response to osteoporosis therapies. Bone $35: 1003,(2004)$.

23. Kanou M, Ueno T, Kagawa T, et al. Osteogenic potential of primed periosteum graft in the rat calvarial model. Ann Plast Surg 54:71, (2005).

24. Malizos KN, Papatheodorou LK. The healing potential of the periosteum molecular aspects. Injury 36(suppl 3):S13, (2005).

25. Huh JY, Choi BH, Kim BY, et al. Critical size defect in the canine mandible. Oral Surg Oral Med Oral Pathol Oral Radiol Endod 100:296, (2005).
26. Feng Xuan, MD, Chun-Ui Lee, DDS. Vertical Ridge Augmentation Using Xenogenous Bone Blocks: A Comparison between the Flap and Tunneling Procedures J Oral Maxillofac Surg, 72:1660-1670, 2014 (2014).

27. Oscar Hasson, DDS, a Rehovot. Augmentation of deficient lateral alveolar ridge using the subperiosteal tunneling dissection approach Oral Surg Oral Med Oral Pathol Oral Radiol Endod; 103:e14-e19 (2007).

28. Craig MM. Implant site development using ridge splitting techniques.Oral MaxilloFacial Surg Clin North Am; 16:65-74 (2004).

29. Block MS. Treatment of the single tooth extraction site. Oral Maxillofac Surg Clin N Am; 16:41-63 (2004).

30. Marx RE, Morales MJ. Morbidity from bone harvest in the major jaw reconstruction: a randomized trial comparing the lateral anterior and posterior approaches to the ilium. J Oral Maxillofac Surg; 46:196-203 (1988).

31. Sclar AG. Strategies for management of single-tooth extraction sites in aesthetic implant therapy. J Oral Maxillofac Surg; 62(Suppl 2):90-105 (2004).

32. Al-Sebaei MO, Papageorge MB, Woo T. Technique for inoffice cranial bone harvesting. J Oral Maxillofac Surg;62 (Suppl 2):120-2 (2004).

33. Levin L, Ophir S, Schwartz-Arad D. Atrophic ridge augmentation using intraoral onlay bone graftsexpanding the limits. J Isr Dent Assoc; 23:31-5. Hebrew (2006).

34. Herford AS, King BJ, Audia F, Becktor J. Medial approach for tibial bone graft. Anatomic study and clinical technique. J Oral Maxillofac Surg; 61:358-63 (2003).

35. Misch MM. Comparison of intraoral donor sites for onlay grafting prior to implant placement. Int J Oral Maxillofac Implants; 12:767-76 (1997). 